\title{
La dualidad del patrimonio paleontológico y su divulgación
}

\author{
Alberto Leandro Aranda Quirós | graduado en Ciencias Ambientales y Ciencias del Mar
}

URL de la contribución <www.iaph.es/revistaph/index.php/revistaph/article/view/4184>

La necesidad del patrimonio paleontológico de poseer un marco legal propio y específico surge de su propia singularidad. En la actualidad, resulta difícil seleccionar las características que deben primar a la hora de catalogar estos materiales; por un lado, presenta un gran interés cultural, dotando de una nueva identidad a los lugares en los que se ubican los yacimientos, generando de este modo turismo y comercio. Por esto, la asignación de competencias en esta materia debería tener un matiz cultural. Pero no debe olvidarse la información que puede proporcionar estos bienes. Diversas ciencias reciben grandes aportes de datos de fuentes paleontológicas, por lo que el organismo que asuma su gestión ha de contemplar dicha importancia.

Esto lleva a que en el territorio español el patrimonio paleontológico se encuentre sujeto a normativas que atienden principalmente a su valor cultural, por un lado, y por otro al natural. Surge la necesidad de crear un marco legislativo que aúne ambas vertientes, logrando una gestión más precisa del material paleontológico que evite el actual desequilibrio en la gestión de estos bienes, pudiendo encontrarse situaciones en las que favorecer una de estas opciones produce un claro detrimento de las otras colecciones. Es el caso de aquéllas que no se encuentran accesibles para su protección debido a su interés científico; $y$, a su vez, otras en las que su explotación cultural genera unas presiones que acaba generando una degradación.

Como ya se ha mencionado el aporte de datos que puede generar la paleontología a otras áreas del conocimiento como la biología y la geología es incalculable. Dado a su magnitud temporal, el estudio de la vida anterior a la aparición del ser humano carece de cualquier dato que no provenga de fuentes paleontológicas: primeras formas de vida, evolución de las especies, la extinción de las mismas... Para el caso de la geología, el uso de fósiles permite caracterizar los materiales en los que se encuentran, diferenciado medios de formación (marino, terrestre...) o aportando una escala temporal, entre otras. De una forma más generalista puede asumirse que casi cualquier estudio que incluya una escala temporal requerirá alguna forma el uso de información paleontológica.

Quedando patente la gran importancia que presentan estos materiales para la ciencia, es en este punto, cuando debe aparecer la figura del paleontólogo. La creación de una normativa propia y su aplicación sobre este patrimonio ha de ser desarrollada por profesionales que conozcan todas las características del mismo. Los paleontólogos deben evaluar la importancia de cada pieza y decidir que cuáles podrían ser explotados culturalmente, aún a riesgo de su perdida, y cuáles deben ser conservados para un uso científico debido a sus excepcionales características. De esta forma, podría por ejemplo diferenciarse entre la gestión realizada sobre el ejemplar de Concavenator corcovatus, descubierto en Cuenca y único a nivel mundial, y la gestión realizada sobre la innumerables valvas de Glycymerys sp. presentes en el Golfo de Cádiz.

Si se quiere realizar una gestión precisa de estos bienes, la formación del paleontólogo tendrá que tener un enfoque multidisciplinar, de tal forma que pueda encargarse del tratamiento del material desde su descubrimiento y extracción hasta su exposición, pasando por el diverso trabajo de investigación que requiera cada pieza, para el caso de los bienes muebles, y desde su localización hasta su adecuación final, incluyendo las diversas actuaciones que allí se realicen para el caso de los bienes inmuebles. El trabajo de restauración por parte de especialistas en materias artísticas puede presentar discre- 
a debate El marco legal para la protección del patrimonio paleontológico. ¿Qué pasa en tu comunidad?

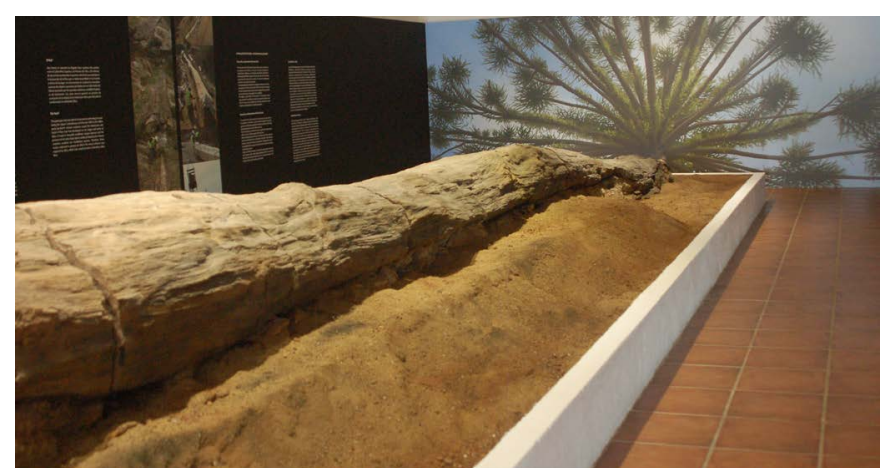

Tronco de araucaria fosilizado, perteneciente al periodo Cuaternario. Almadén de la Plata (Sevilla). Hallado en 2015 de forma fortuita este tronco fosilizado de 17 metros de longitud y más de 12 toneladas de peso es un ejemplar excepcional a nivel europeo por su tamaño y buen estado de conservación. Tras un complejo proceso de extracción y restauración la empresa Dédalo Bienes Culturales SL acometió un plan de exposición e interpretación global | foto Dédalo Bienes Culturales sl

pancias con el resultado que el investigador necesita, pudiendo producir demoras o daños no intencionados. A fin de disminuir la posibilidad de que se presenten estos inconvenientes, sería necesario formar al investigador en restauración, pudiendo así el paleontólogo desarrollar ambas acciones y por tanto maximizando la protección del patrimonio.

Por último, el paleontólogo debe encargarse de la divulgación de la ciencia que estudia; el primer paso para que la población comprenda la importancia del patrimonio paleontológico es que lo conozca.

Las nuevas tecnologías pueden presentar un papel muy importante a la hora de llevar a cabo esta divulgación. Gracias a las redes sociales toda información vertida a la red es susceptible de llegar a cualquier parte del mundo; debido a esta posibilidad de interacción en ambas direcciones, la comunicación y por tanto la capacidad para mostrar el valor del patrimonio paleontológico es más alta que nunca.

Desde un punto de vista específico el avance de las tecnologías ha favorecido la conservación de diversos especímenes, favoreciendo un estudio menos invasivo y la capacidad de fabricar réplicas de mayor calidad. Esto se traduce en la posibilidad de poder realizar aná- lisis que mediante otras técnicas habría causado daños o bien evitar dañar durante su exposición o transporte. En estos momentos las mejoras en tecnología 3D están permitiendo la reconstrucción y el intercambio de una información muy precisa, que en los próximos tiempos y gracias al auge de la impresión 3D conseguirá un avance tanto en materia divulgativa, construcción de réplicas en cualquier lugar procedentes a su vez de cualquier lugar, como científica, permitiendo la reconstrucción de piezas incompletas.

Para lograr la conservación del patrimonio paleontológico es necesario la ubicación en el lugar administrativo correcto y siempre sujeto a la supervisión de profesionales competentes. Por último no se deberá olvidar la necesidad de divulgación, ya que los paleontólogos ya conocen el valor de este patrimonio y en este momento es necesario que sea la sociedad quien conozca dicho valor. 